\title{
Design of Application Architecture for 3D Safety Status Information Platform ${ }^{1}$
}

\author{
T. Kim*, J. Youn, D. Kim, W. Choi
}

\begin{abstract}
Department of Future Technology and Convergence Research, Korean Institute of Civil Engineering and Building Technology (KICT), 283, Goyangdae-ro, Ilsanseo-gu, Goyang-si, Gyeonggi-do, 10223, Rep. of Korea - (kth, younj, dusikkim,wcchoi)@kict.re.kr
\end{abstract}

KEY WORDS: Disaster Management, Safety Index Map, 3D Spatial Information, Safety Status Information Platform, Application Architecture

\begin{abstract}
:
The Korean Government has executed the research project named "The development of spatial information-based high-reality contents provision technology for disaster management". The goal of this project is to develop and verify a Safety Index Map and a 3D safety status information platform for spatial information based customized disaster management service. This paper deals with the design of application architecture for spatial information based 3D safety state information platform. First, we analysed the use cases of existing disaster management platform and the needs of business users. Second, based on the analysed results, target facilities were selected and possible service scenarios were created. Finally, we designed application architecture with service development strategy and users' requirements. The results of this research could be used for detail design of technical architectures (DA/SA/HA/NA).
\end{abstract}

\section{INTRODUCTION}

Major natural disasters such as typhoons, earthquakes, tsunamis and droughts continue to increase due to climate change associated with global warming. In addition, social disasters such as complex disasters and fire associated with urbanization and SOC infrastructure dilapidation, as well as infectious diseases continue to rise. Especially in urban areas, in the case of disaster occurrence, intensive human and material damage is highly likely to occur due to population concentration and an increase in various buildings and SOC facilities. However, since Korea generally does not properly recognize the risk of disasters and is politically and technically passive in predicting and preventing disasters, damage to buildings and facilities will be devastating in the event of unforeseen disasters. In addition, the existing after-accident recovery planning is obviously limited in its effects, and cannot properly cope with the increasing disaster threats and damages so it is imperative to change the way of thinking about disaster handling measures into the prediction and response planning system (Park, 2013).

In order to predict, prevent and prepare for such disasters, major developed countries are developing computerized simulations and response platforms through mid- and long-term research and development. Through these researches, they are striving to establish integrated and efficient management systems designed to ensure the cause definition, disaster prediction, disaster risk evaluation, disaster spread prediction, quick response to disasters and support for recovery.

In Korea, the Ministry of Science and ICT has been working on three areas (disaster detection, disaster prediction, and disaster response) and 6 core platform technologies (such as the standardization and integration of disaster monitoring information, unmanned disaster detection and response, composite disaster simulation, composite disaster simulation platforms, core materials for the disaster rescue equipment, disaster site equipment and personnel) presented in the 10-year roadmap for disaster science and technology development (Ministry of Science, 2015). Oh et al. (2012) proposed a conceptual framework for linking the building information modelling (BIM) and sensor information model to ensure realtime facility disaster management. Ryu et al. (2014) proposed an integrated model of the IFC (Industry Foundation Classes) which is a standard model of architectural information modelling for ensuring efficient urban infrastructure management, and the CityGML which is a standard model of spatial information (Oh, et al., 2012; Ryu and Seung, 2014). Gang et al. (2017) pointed out that spatial information is based on real $3 \mathrm{D}$ while a disaster analysis indicates that the $2 \mathrm{D}$ information is less accurate and limited, and that 3D-based research is increasingly being conducted. They thus researched and developed a core module for unity-based 3D visualization platform (Gang et al., 2017). However, the development of these technologies are still in the early stage, and efforts are still insufficient to develop and use the systems or platforms combined with spatial location information and attribute information.

In this study, in order to develop a 3D safety state information platform based on the spatial information of urban public facilities, investigations and analysis of the developing and existing disaster management platforms were proceeded as well as analysing user requirements. Second, based on the analysed results, the various target facilities were selected and scenarios of possible disaster response were prepared. Third, an application architecture for 3D safety status information platform was designed, and major service development methods were presented.

\footnotetext{
1 This paper is an enriched and revised version of a paper presented at the Journal of the Korean Academia-Industrial cooperation Society, 2019

* Corresponding author
} 


\section{INVESTIGATION OF CASES OF DEVELOPMENT OF DISASTER RESPONSE PLATFORMS AND ANALYSIS OF USER REQUIREMENTS}

The development and research of disaster response platform technologies in Korea is mainly conducted by the Ministry of the Interior and Safety (MOIS), the Ministry of Science, Technology, Information and Communication (formerly), the Ministry of Land, Infrastructure and Transport (MOLIT), and other related government ministries and public institutions. Planned government-financed projects also are underway in this regard while some schools, etc. are conducting research on related elementary technologies. MOIS developed a scenariobased large complex disaster spread prediction technology ('17 `18)" to establish inter-model optimal linkage modelling basis in preparation for the occurrence of complex disasters, and developed Smart Big Boards to develop the big data- and ICTapplied smart situation management system for use by local governments. Starting with "Disaster Safety Information Sharing Platform (16 '20)", "Intelligent Risk Analysis and Damage Prediction-based Fire Response Platform ('17 '20)", "Multimedia-based Disaster Information Delivery Platform (18 '21)", etc. among the six core platform projects, the Ministry of Science and ICT (MSIT) is pushing ahead with the development of core technologies (Ministry of Science, 2015). Under the "Integrated Safety Management Platform Waterside Structures ('13 '18)" project, MOLIT, based on the electronicgovernment framework, conducts a real-time integrated safety evaluation of waterside structures, and offers a decision-making support system designed for damage analysis and recovery work support (ISMRC, 2016). Further, the Fusion Technology Research Center of the National Research Council of Science \& Technology (NST) is conducting the 'Development of Integrated Information Platform for Super-High-Rise Buildings and Complex Facilities in Disaster Damage Response ('16 '19)'. As such, NST is focusing on the development of the open platform server (architecture information modelling/GIS $3 \mathrm{D}$ information-based platform) and integrated CPS (scenariobased situation response control/evacuation/judgment services) (Park et al., 2017). The analysis of such existing disaster response platform development projects revealed that, in many cases, they investigated and analysed the past response cases and work processes to set the direction, and that, based on the Disaster Response SOP, they conducted a mapping of work and information, thus displaying the results in diagram to be used in the construction of platforms (Seo et al., 2017).

The U.S. FEMA uses HAZUS-MH - which is software designed to evaluate the risk of disaster based on the map of risks of earthquakes, hurricanes, floods, etc. -, to evaluate the impact of an accident before its outbreak, to establish emergency response/recovery plans, and to estimate the damage/loss size. The U.S. NFIRS operates an information system in order to manage huge databases on fire accidents. The U.S. NIST, under the Smart Fighting Project, carried out research on the fusion of sensor and computing technologies, building control systems, firefighting equipment and devices (NIST, 2015). In addition, EU, under the smart@fire project, developed the sensor technology for measuring the fire scene environment information and firefighters' biomechanics, and the technology designed for data transmission and visualization for the purpose of ensuring an accurate recognition of the fire scene. In order to identify the actual disaster safety management by the field operations and buildings for the target of research, this study surveyed the disaster safety staff at MOIS, Fire \& Disaster Headquarters, local governments, Office Of Education, and other public-use facilities, to analyse the current state and to survey the user requirements. As a result, Gyeonggi-do Fire \& Disaster Headquarters recommended to research the dilapidated buildings with high risk of safety against disasters (class D and $\mathrm{E}$ in redevelopment areas), and identified an appropriate division of the evacuation paths of evacuees in the event of an accident, naming of individual emergency exits, the real-time evacuee location identification, etc. The Citizen Safety Section of Goyang City recommended to research small-scale healthcare facilities, etc. with insufficient capabilities for responding to disasters and for ensuring safety, and it was revealed that they need to receive the support services involving a quick initial response, and the combined operation of CCTV and mobile phones, and to adopt the coding system and location-based management for the public-use facilities. Sejong City Office of Education recommended investigating the new buildings of elementary school, and we requested that they need to adopt the system and bolster the response capabilities for ensuring safety against disasters due to a shortage of experts in safety against disasters in schools. In addition, it was analysed that they should adopt manuals-based systems and that if they provide tailored services (situation management + public address + mobile) to each response group, it will bring big effects. MOIS expressed a view that, of the public-use facilities, the superhigh-rise buildings have already commercial systems, that hospitals have the problem of being accessed, that the Dangerous Goods Management Corporation would be difficult to select for the target of research because it would be fit for the future expansion construction, and that there is a need to select the facilities which have a high population density and that are used by the evacuation impaired people and to analyse the past statistics.

\section{SELECTION OF TARGET FACILITIES AND WRITING OF POSSIBLE SCENARIOS}

Based on the results of an analysis of the management agency user requirements in relation to the public-use facilities, the satisfaction conditions of the target buildings were derived and described below. First, they have a high population density. Second, they are used by evacuation and safety impaired people (children, the elderly, patients, disabled people, etc.). Third, they are the target of inspection through regular firefighting activity. Fourth, they are equipped with sensors related to safety against disasters and firefighting. Fifth, they transferred the development system and have an operation team (members). Considering the meeting of relevant conditions and the managers' (users) recommendation, the final targets of research came down to healthcare facilities, schools, and dilapidated buildings. A factor analysis thereof is described in Table I.

\begin{tabular}{|l|l|l|l|}
\hline \multirow{2}{*}{ Factor } & \multicolumn{3}{|c|}{ Candidate building } \\
\cline { 2 - 4 } & $\begin{array}{c}\text { Nursing } \\
\text { facility }\end{array}$ & \multicolumn{1}{|c|}{ Old building } & \multicolumn{1}{|c|}{ School } \\
\hline $\begin{array}{l}\text { Number of } \\
\text { users }\end{array}$ & high & low & high \\
\hline Main user & patient & $\begin{array}{l}\text { regular } \\
\text { citizen }\end{array}$ & student \\
\hline $\begin{array}{l}\text { Disaster/ } \\
\text { Safety } \\
\text { vulnerabilit } \\
\text { y }\end{array}$ & medium & high & low \\
\hline Impact & high & medium & high \\
\hline Frequency & medium & high & low \\
\hline
\end{tabular}




\begin{tabular}{|l|l|l|l|}
\hline $\begin{array}{l}\text { Installed } \\
\text { sensor }\end{array}$ & existence & insufficiency & existence \\
\hline $\begin{array}{l}\text { System } \\
\text { transfer } \\
\text { agency }\end{array}$ & existence & insufficiency & existence \\
\hline
\end{tabular}

Table 1. Description of application function for real-time volcanic disaster prediction

Healthcare hospitals, healthcare facilities, etc. are recently increasing in number due to population aging, are used by many people, and are difficult to evacuate in the event of disaster occurrence. Schools have not relatively high frequency of accidents and high vulnerability but they accommodate many students densely, and in the event of a disaster, they will be greatly affected, and education and training about safety against disasters will likely offer big effects and ripple effects. Dilapidated buildings have a little low resident density, but they are highly vulnerable to disasters due to the dilapidation of fire response systems and they are increasingly hit with disasters, for which reason they were selected as the target of investigation. Regarding the three types of public-use facilities for the target of research, user requirements were analysed, the site response or crisis situation response manuals, and the existing safety response systems for disasters, etc. were also analysed so that scenarios for disaster occurrences (fire, earthquake, etc.) were prepared as shown on Fig. 1 and Fig. 2. The scenario is the outline of a chain of stories and description according to the flow of time, and it should be prepared in the form of description or in the form of timetable. The scenario advantage is not about the simple prediction, but about resolving the future uncertainties positively to ensure the desired future results and about helping a systematic planning. Thus, this study established four components - response procedure, timeline, disaster impact and response entity, and involvement by the related agency - in order to develop specific scenarios. First, the response procedure is defined as the procedure after referring to the existing manuals on crisis situation response according to public-use facilities. Second, the timeline sets the flow of time, from disaster outbreak, to situation recognition and confirmation, situation announcement, initial response, and evacuation completion according to the development of situations. It was determined as the time flow element. Third, the impact of disaster and response entity consist of the safety manager (disaster prevention situation room), firefighting group, evacuation guide group, related agency, evacuees, residents, etc. according to impacts and entities in relation to the occurrence of disaster. Involvement by the related agency consists of local governments, hospitals and other public institutions that are responsible for ensuring safety against disaster and for responding to disasters. In writing scenarios, the information and action related to safety against disaster that enables the linkage of such individual factors were mapped so that the whole scenario was made to unfold.

Fig. 1 is a scenario developed by assuming a fire outbreak in a healthcare hospital. As such, this 3D safety state information platform, linked to the existing fire sensor and system, was installed. It was assumed that the resident detection, situation recognition and optimum evacuation path, public address for responding to situation, automatic texting of information, among other service functions, were implemented. The elderly and weak or patients who have difficulty evacuating quickly were considered. Fig. 2 assumed an earthquake outbreak in elementary school. As with Fig 1, the platform and service system were constructed, and the characteristics of earthquake damage and residents as elementary school students were reflected in the scenario. The related agency was required to speedily provide the disaster occurrence situation information, impact spread information, evacuees information, residents information, building drawing information, firefighting facilities information, etc. so as to minimize the damage.

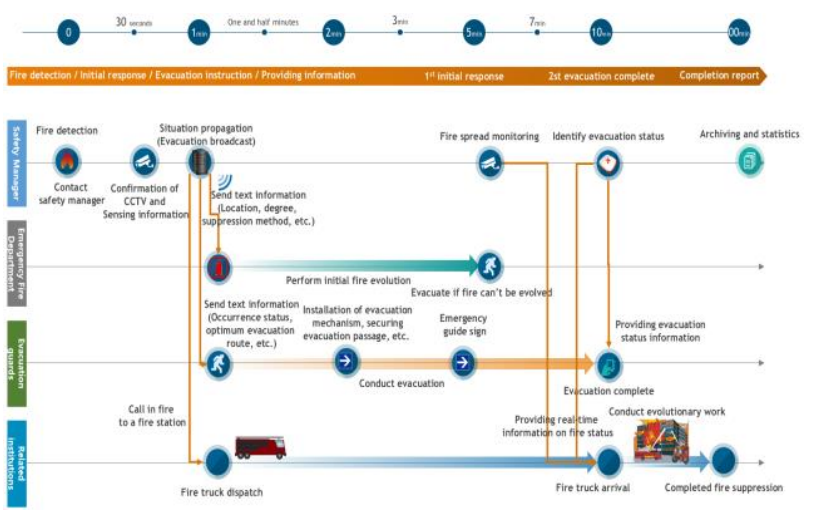

Figure 1. Fire response scenario in nursing hospital

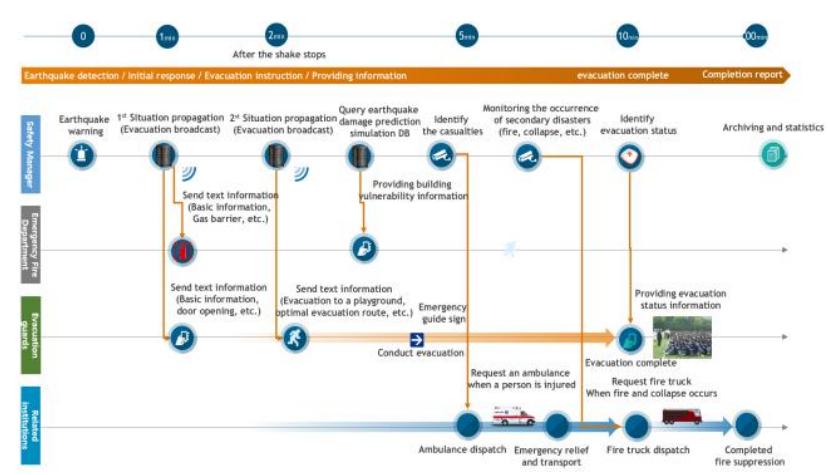

Figure 2. Earthquake response scenario in nursing hospital

\section{DESIGN OF PLATFORM APPLICATION ARCHITECTURE AND SERVICE DEVELOPMENT MEASURES}

In order to actively develop the 3D safety state information platform designed for the spatial information-based real-sensetype management of disasters, the application architecture design and service measures are required. The '3D safety state information platform' displays and manages the targets' safety state situation based on the standard safety model and on the time-varying safety state information, and it means the platform that provides diverse safety services against disasters. Specifically, the platform is equipped with the standard safety model of buildings and facilities in the target area, based on the $3 \mathrm{D}$ interior and exterior spatial information so as to periodically renew the safety state situation information that is ever changing according to events and time, to visualize the information in $3 \mathrm{D}$, to provide service functions such as the alarm about danger, prediction of structural damage of buildings, the damage reduction measures and linkage to the outside.

To that end, based on the analysis of the existing platforms, analysis of user requirements, determination of scenarios, etc. which were performed in the Chapters 2 and 3, the functional scope of the necessary platform was compared with the existing 
platforms to handle the target buildings and future services so as to derive Table 2 .

\begin{tabular}{|c|c|c|c|c|}
\hline Factor & $\begin{array}{c}\text { BIM/GI } \\
\text { S } \\
\text { Platform }\end{array}$ & $\begin{array}{l}\text { Smart } \\
\text { Big } \\
\text { Board }\end{array}$ & $\begin{array}{c}\text { CPS } \\
\text { Platform }\end{array}$ & $\begin{array}{l}\text { 3D Safety } \\
\text { status } \\
\text { informatio } \\
\text { n Platform }\end{array}$ \\
\hline Service type & $\begin{array}{l}\text { 2D/3D } \\
\text { Web, } \\
\text { C/S }\end{array}$ & $\begin{array}{c}2 \mathrm{D} \\
\mathrm{Web}\end{array}$ & $\begin{array}{c}2 \mathrm{D} / 3 \mathrm{D} \\
\mathrm{C} / \mathrm{S}\end{array}$ & $\begin{array}{l}2 \mathrm{D} / 3 \mathrm{D} \\
\text { Web }\end{array}$ \\
\hline $\begin{array}{l}\text { National } \\
\text { spatial } \\
\text { information } \\
\text { (Map, Vector, } \\
\text { POI) }\end{array}$ & $\sqrt{ }$ & $\sqrt{ }$ & $\sqrt{ }$ & $\sqrt{ }$ \\
\hline $\begin{array}{l}\text { Related } \\
\text { institution } \\
\text { information }\end{array}$ & $\sqrt{ }$ & $\sqrt{ }$ & $\sqrt{ }$ & $\sqrt{ }$ \\
\hline $\begin{array}{l}\text { Scope of } \\
\text { application }\end{array}$ & Site & City & $\begin{array}{c}\text { Site } \\
\text { (skyscra } \\
\text { per) }\end{array}$ & Site-City \\
\hline $\begin{array}{l}\text { Indoor and } \\
\text { outdoor } \\
\text { connection }\end{array}$ & $\sqrt{ }$ & & $\sqrt{ }$ & $\sqrt{ }$ \\
\hline $\begin{array}{l}\text { Analysis } \\
\text { simulation }\end{array}$ & & $\sqrt{ }$ & $\sqrt{ }$ & $\sqrt{ }$ \\
\hline $\begin{array}{l}\text { Unstructured } \\
\text { data }\end{array}$ & & $\sqrt{ }$ & $\sqrt{ }$ & $\sqrt{ }$ \\
\hline $\begin{array}{l}\text { Building } \\
\text { Information } \\
\text { Link }\end{array}$ & $\sqrt{ }$ & & $\sqrt{ }$ & $\sqrt{ }$ \\
\hline $\begin{array}{l}\text { Ground } \\
\text { Information }\end{array}$ & & & $\sqrt{ }$ & $\sqrt{ }$ \\
\hline $\begin{array}{l}\text { Sensing } \\
\text { Information } \\
\text { Link } \\
\end{array}$ & & $\sqrt{ }$ & $\sqrt{ }$ & $\sqrt{ }$ \\
\hline $\begin{array}{l}\text { Safety status } \\
\text { information }\end{array}$ & & & & $\sqrt{ }$ \\
\hline
\end{tabular}

Table 2. Extraction of platform functional scope

The derived functional elements were reflected to derive the architecture of the 3D safety state information platform, and the overall upper-concept flow and application architecture are illustrated in Fig. 3 and Fig. 4

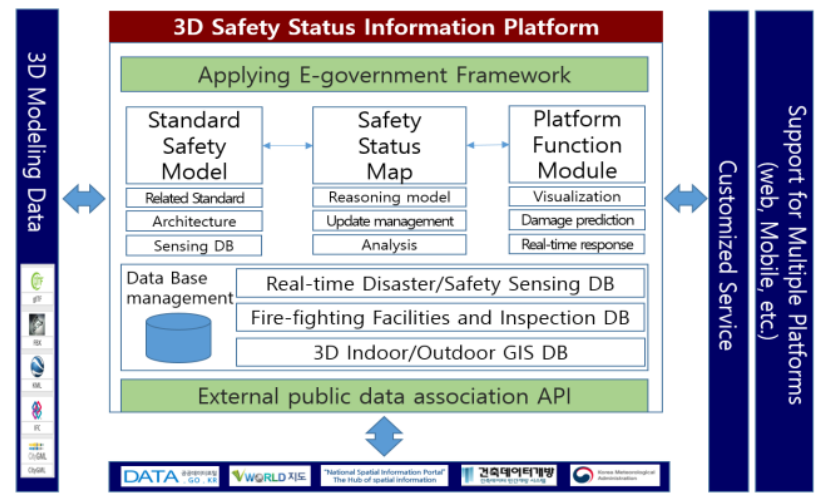

Figure 3. Conceptual diagram for 3D safety status information platform architecture

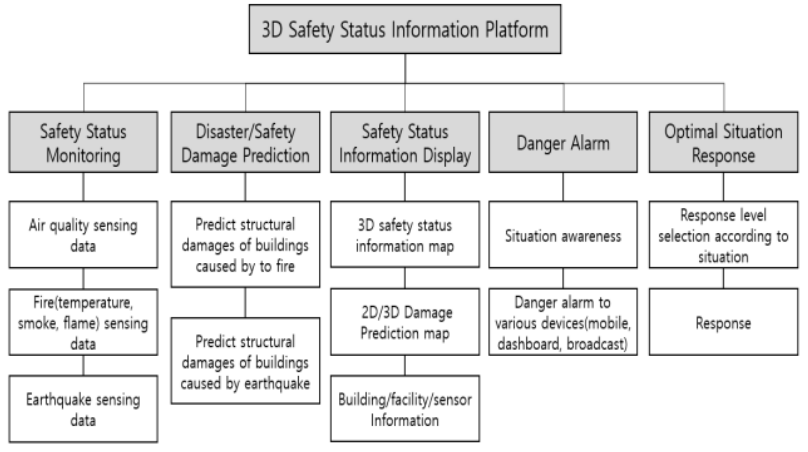

Figure 4. Application architecture for 3D safety status information platform architecture

This platform, which should basically use the information on the design and modelling of buildings such as public-use facilities, must support not only the 3D-modeling data such as gITF (GL Transmission Format), FBX (Filmbox), KML (Keyhole Markup Language), and CityGML (City Geography Markup Language), but also IFC which is the standard exchange information model of building information modelling. The platform basically visualizes the safety state information of target buildings based on the standard safety model in the form of a map to display the situation information, and provides diverse service functions using the real-time sensing DB, DB of firefighting facilities inspection, and $\mathrm{DB}$ of $3 \mathrm{D}$ building interiors and exteriors. In order to implement diverse service functions, the platform links to public information open platforms such as national spatial information, statistical information, and disaster and safety information to obtain and use the relevant information, and is designed to use provide the customized services according to users such as building safety managers, staff for safety against disasters at local governments, and relevant government staffers, using the diverse devices including mobiles and Web.

Considering the user requirement analysis, determination of the platform function scope, architecture flow, etc., the major service items provided by this platform are shown in Table 3 , and the detailed contents are described below.

\begin{tabular}{|c|l|l|}
\hline No. & $\begin{array}{l}\text { Results of user needs } \\
\text { analysis }\end{array}$ & \multicolumn{1}{|c|}{ Service Name } \\
\hline 1 & $\begin{array}{l}\text { Lack of permanent } \\
\text { disaster safety } \\
\text { monitoring } \\
\text { management system }\end{array}$ & $\begin{array}{l}\text { Real-time monitoring service } \\
\text { based on sensing information } \\
\text { and CCTV }\end{array}$ \\
\hline 2 & $\begin{array}{l}\text { Inadequate method of } \\
\text { propagating the } \\
\text { situation } \\
\text { in the event of a } \\
\text { disaster }\end{array}$ & $\begin{array}{l}\text { Mobile and broadcast-linked } \\
\text { risk alarm service }\end{array}$ \\
\hline 3 & $\begin{array}{l}\text { service for prediction } \\
\text { of disaster damage of } \\
\text { buildings }\end{array}$ & $\begin{array}{l}\text { Structural Damage } \\
\text { Prediction Service for } \\
\text { Building Based on } \\
\text { Simulation }\end{array}$ \\
\hline 4 & $\begin{array}{l}\text { Lack of customized } \\
\text { response information } \\
\text { according to disaster } \\
\text { situation }\end{array}$ & $\begin{array}{l}\text { Optimal Response Guidance } \\
\text { Service by Situation/Target }\end{array}$ \\
\hline
\end{tabular}




\begin{tabular}{|c|l|l|}
\hline 5 & $\begin{array}{l}\text { Inadequate system for } \\
\text { providing information } \\
\text { on related } \\
\text { organizations in } \\
\text { case of disaster }\end{array}$ & $\begin{array}{l}\text { Optimal Information } \\
\text { Delivery Service for Related } \\
\text { Agencies } \times\end{array}$ \\
\hline
\end{tabular}

Table 3. Platform service list

First, the real-time sensing information and CCTV-based monitoring services means the services that, based on the sensing values of the diverse fire detection sensors installed in the building, of earthquake detection sensors, measurement sensors and the like, of images of CCTVs installed in various places, and of residents-identification sensors and the like, conduct the real-time monitoring of dangerous situations in the building and analyse the relevant information so as to continuously provide the safety state information.

Second, the mobile and public address system-linked disaster danger alarm services refer to the alarm about disaster dangers that is issued by an automatic linking to the existing broadcasting system and mobile devices in order to quickly and clearly inform the safety mangers, residents and the like in the building (facility) of the disaster occurrence information and situation information.

Third, the simulation-based building structure damage prediction services refer to the services which reinforce the vulnerable part before a disaster occurrence by simulating and databasing the damage impact of building pillars, walls and the like due to fires and earthquakes, and which promptly inform safety managers or relevant agencies of the possible collapse part in the building or vulnerable part in the actual disaster occurrence, and other situation information so as to minimize the damage.

Fourth, the optimum response information services by situation and target selectively and intensively provide the necessary information (the provision of actions needed according to the crisis situation response manuals, the provision of an optimum evacuation path ever changing according to situations, the provision of optimum response measures by situation and the like) that vary based on the ever-changing disaster situation according to the disaster occurrence location, spread and the like in the building according to the disaster types such as fire, earthquake, and building collapse, and that should be practiced and recognized by the response team (situation manager, emergency response group, and evacuation group), residents, firefighting headquarters and other targets, so as to promptly respond to the urgent situation.

Lastly, the relevant agency-linked optimum information provision services refer to the services that, by linking to relevant agencies based on the systems, promptly and continuously provide the continuously monitored disaster situation information on the disaster occurrence, spread and the like, the interior and exterior spatial information, the building design information, the information on residents and evacuees, the information on firefighting facilities and dangerous facilities, and other important information needed for responding to disaster situations.

\section{CONCLUSION}

In this study, the practical 3D safety state information platform for public-use facilities was developed by investigating and analysing cases of the existing similar disaster platforms, and by surveying the public-sue facilities managers to analyse user requirements. In addition, target facilities were selected, and scenarios were written about the possible fires, earthquakes and other disasters in the target facilities. From this information, the architecture and functional scope of the 3D safety state information platform were derived, and major service items were presented. Five major services were derived: first, the realtime sensing information and CCTV-based monitoring services; second, mobile and public address system-linked disaster alarm services; third, the simulation-based building structure damage prediction services; fourth, the optimum response information services by situation and target; and fifth, the relevant-linked optimum information provision services.

Based on these findings of this study, efforts will be made to design and develop the technical architecture (DA/SA/HA/NA) of the 3D safety sate information platform, to conduct test bed demonstration, and to transfer the system so as to enable the management of disasters in public-use facilities and to pursue commercialization of the system. If this technology is commercialized successfully and spreads, it is expected to help improve the safety and disaster response capabilities in publicuse facilities, and at the same

\section{ACKNOWLEDGEMENTS}

This research was supported by a grant (19DRMS-B146826-02) from Development of Customized Contents Provision Technology for Realistic Disaster Management Based on Spatial Information Program funded by Ministry of the Interior and Safety of Korean government.

\section{REFERENCES}

Park, M., 2013. Disaster Management of Building and Distributed Simulation Platform, Journal of Architectural Institute of Korea, 57(3), pp.32-36.

Ministry of Science, 2015. ICT and Future Planning, Technical Report, Disaster Safety Platform Technology Development Project in Korea, pp.1-2.

Oh, E., Lee, S., Shin, E., Kang, T., and Lee, Y., 2012. A Framework of Realtime Infrastructure Disaster Management System based on the Integration of the Building Information Model and the Sensor Information Model, Journal of KOSHAM, 12(6), pp.7-14

Ryu, R., and Seung, Y., 2014. A Basic Study of iBUM Development based on BIM/GIS Standard Information for Construction of Spatial Database, Journal of Korea Spatial Information Society, 22(5), pp.27-41.

Gang, S., Ryu, D., Kim, T., Park, H., Kim, J., and Choung, Y., 2017. Development of Core Module and Web System for a Visualization Platform for the 3D GIS Service of Disaster Information using Unity, Journal of Korea Multimedia Society, 20(3), pp.520-532.

Integrated Safety Management Research Center for Waterside Structures, 2016. PR brochure in Korea, Integrated safety management platform for water infrastructure (WINS'), pp.6-7.

Park, S., Hong, C., Youn, C., and Kim, G., 2017. A Study on the Implementation of a Disaster Countermeasure Integrated Information Platform for Complex Skyscraper Facilities, The Proceedings of KSCE Conference, pp.8-9.

Seo, H., Min, G., and Jung, D., 2017. On the development of a scenario-based disaster safety information platform, The 
Proceedings of Korea Intelligent Information Systems Society Conference, pp.64-65.

NIST, 2015. Research Roadmap for Smart Fire Fighting, NIST Special Publication 1191. 